\title{
A EDUCAÇÃO AMBIENTAL, SUA COMPREENSÃO DA VISÃO CULTURAL DO DESENVOLVIMENTO
}

\author{
Environmental Education, its understanding the cultural vision of development
}

\section{Resumo}

Este artigo aborda algumas ideias sobre a importância da criação de uma educação ambiental eficiente, que se em frente do sala-de-aula e fora dela aos absurdos do patrão desenfreado de produção e consume, uma problemática que vai sendo uma provocação para os educadores em cada lugar do planeta. A escola constitui um espaço privilegiado para a educação de valores ambientais, os quais se constituem no fundamento das atitudes positivas e os comportamentos responsáveis onde o professor tem uma função essencial na direção deste processo de formação.

\begin{abstract}
This article deals with some ideas about the importance of the creation of an efficient environmental education that faces the challenges of wrong production and comsumption patterns established.In this respect the school constitutes a place of paramount importance for an education of environmental values, therefore the teacher has an essencial function as a leader in this fromative process.
\end{abstract}

Palavras-chave: Educação Ambiental; Valores Ambientais, Processo Formativo.

Key-words: Environmental Education; Environmental Values; Formative Process.

Data de submissão: janeiro 2019 | Data de publicação: setembro 2019.

${ }^{1}$ FRANCISCO JACUCHA CAHUCO KIMBANDA - Escola Superior Pedagógica do Bengo. ANGOLA. E-mail: franciscojacucha1@gmail.com. 


\section{INTRODUÇÃO}

O reconhecimento mundial da existência de uma crise ambiental, não só foi um preocupam-se chamado de alerta ante a depredação, a perda de recursos e a contaminação estendida já por todo o planeta, mas sim também conduziu ao reconhecimento de uma crise de nossa mesma "civilização". A solução desta crise não se encontra simplesmente na recuperação ou melhor uso dos recursos naturais, ou em respostas tecnológicas para conseguir minimizar o desastre, mas sim tem que buscar-se no sustento ético e filosófico do pensamento social e econômico, nos novos paradigmas das ciências e da educação e na percepção e aplicação dos postulados éticos e educativos do desenvolvimento a que a humanidade aspira.

Há alguns anos está em curso em Angola uma reforma educativa, convertida em um dos grandes desafios vividos hoje nas instituições escolar, em busca de novas metodologias que facilitem o desenvolvimento do processo de ensino aprendizagem. Entre esses desafios está o fato de enfrentar a deterioração do meio ambiente com políticas e práticas educacionais sustentáveis, implementando um processo de educação ambiental coerente e sistemático. A Educação Ambiental é, sem dúvida, um dos meios mais indicados para o resgate de valores que incluem o respeito pela diversidade cultural e biológica, fundamental para a conservação e para a convivência gaita das diferentes culturas com a natureza e o amparo do meio ambiente.

A Declaração da conferência das Nações Unidas sobre o meio humano em 1972 proclamou que o homem é de uma vez obra e artífice do meio que o rodeia, o qual lhe dá sustento material e lhe brinda a oportunidade de desenvolver-se intelectual, moral, social e espiritualmente. "O amparo e melhoramento do meio humano é uma questão fundamental que afeta ao bem-estar dos povos e ao desenvolvimento econômico do mundo inteiro, um desejo urgente dos povos de todo o mundo e um dever de todos os governos" (UN, 1972) ${ }^{2}$.

${ }^{2}$ Ver: Conferência das Nações Unidas sobre o Meio Humano, reunida em Estocolmo do 5 aos 16 de junho de 1972. 


\section{MUDANÇA DE PARADIGMA/VISÃO CULTURAL DO DESENVOLVIMENTO}

Ao longo de sua história, Angola veio registrando um intenso processo de deterioração ambiental. As causas de tal situação estão vinculadas estreitamente ao modelo de desenvolvimento econômico adotado do início da colonização. Um país de perto de 14 milhões de pessoas, do que quase o 50\% vive em áreas urbanas, particularmente na bandagem litorânea.

Não obstante, a maioria da população vive em áreas rurais, sem poder retornar a suas terras de origem depois de terminada a guerra que desbastou ao país. Esta população utiliza os recursos naturais como sistema de suporte de suas vidas. daqui que os processos da educação ambiental no contexto descrito tenham que estar intimamente ligados a questões de sobrevivência, desenvolvimento, melhoria da qualidade da educação e o nível de vida das pessoas.

Recursos como a lenha, as áreas de pastoreio, as práticas da agricultura, a água, a flora, a fauna, estão continuamente em função de satisfazer as necessidades da população, e por ende cada vez mais ameaçadas, devido ao aumento de população, a pobreza extrema que afeta várias áreas do pais, e o consumismo irracional de alguns setores sociais. Unido a tudo isto se sofrem as limitações do ensino e o deficiente acesso à educação de postgrado.

A Conferência das Nações Unidas sobre o Meio ambiente e o Desenvolvimento, ${ }^{3}$ havendo-se reunido em Rio do Janeiro do 3 aos 14 de junho de 1992, reafirmou a Declaração da conferência das Nações Unidas sobre o Meio Humano, aprovada em Estocolmo em 16 de Junho de 1972, e apoiando-se nela, definiu os princípios inescapáveis para o trabalho médio ambiental, e por ende a educação ambiental no planeta. Fez ênfase na necessidade de promover o desenvolvimento sustentável, eliminando as modalidades de produção e consumos irracionais que levam a consumismo e à deterioração do planeta. Neste cenário, e tendo como base a perspectiva de reconstrução nacional e melhoria da qualidade de vida da população, é vital o papel da educação e a sensibilidade ambientalista de todos os angolanos.

\footnotetext{
${ }^{3}$ Declaração de Rio sobre o Meio Ambiente e o Desenvolvimento, Rio do Janeiro, junho de 1992. Princípio 8.
} 
A Lei de Base de Meio ambiente em Angola reconhece que "a educação ambiental é uma das medidas de amparo do ambiente cujo objetivo é o aumento progressivo de conhecimentos da população sobre fenômenos ecológicos, sociais e econômicos que regem a sociedade humana" (LBMA, 1998) ${ }^{4}$.

A busca de soluções à problemática ambiental transitou por diferentes variantes; entre elas as que levaram a considerar, em muitos casos, que o problema ecológico poderia ser resolvido somente mediante o desenvolvimento científico-técnico e as novas tecnologias, ou com a ajuda de regulações jurídicas. Apesar da incessante busca de alternativas, tratando de minimizar os problemas a conseqüência da intervenção antrópica, essas concepções tiveram um caráter limitado, e já em Angola começam a discutir-se desde esta perspectiva. Pressupõe-se porque para encontrar possíveis soluções aos problemas ambientais se requer de um enfoque complexo em que se conjuguem e complementem as mais variadas alternativas. Isso deve estar acompanhado, além disso, pelo posicionamento e a tira de decisões políticas por parte dos governos na busca, gestão e solução da problemática ambiental. As propostas para o desenho e posta em marcha de um desenvolvimento sustentável, o surgimento das diversas teorias de sistemas, os esforços para construir e articular novos saberes e ligá-los com os avanços das ciências, as lutas por maior justiça social e por uma verdadeira participação de todos os seres humanos nos processos do desenvolvimento, são portas abertas para ingressar em uma nova etapa de busca de postulados éticos e educativos para obter um equilíbrio dinâmico e de harmonia real entre a sociedade e a natureza (Solís, 2002).

Os paradigmas que sustentam o modelo de desenvolvimento capitalista, dominante no cenário político, social e econômico mundial, impuseram uma determinante hegemônica que configura à maioria dos indivíduos como objetos e não como sujeitos do processo transformador mundial, o que suscita atuações pouco comprometidas com a problemática ambiental. A partir este presuposto pode pensar-se, de um ponto de vista pedagógico, que seria uma utopia imaginar uma educação ambiental real e consciente nas circunstâncias do mundo atual.

\footnotetext{
${ }^{4}$ Lei de Bases do Medio Ambiente (5/98 de 19 junho).
} 


\section{EDUCAÇÃO AMBIENTAL}

Entretanto, a criação de uma educação ambiental eficiente, que se em frente do sala-de-aula e fora dela aos absurdos do patrão desenfreado de produção e consumo desencadeado pela economia de mercado segue sendo uma provocação para os educadores em cada lugar do planeta. A escola constitui um espaço privilegiado para a educação de valores ambientais, os quais se constituem no fundamento das atitudes positivas e os comportamentos responsáveis, e por onde o professor tem uma função essencial na direção deste processo de formativo.

Se aceitarmos o fato de que a sociedade da globalização é um mosaico de graves desequilíbrios territoriais, econômicos e humanos, tal e como expõe a especialista espanhola nos problemas do médio ambiente, María Novo, teríamos que nos expor, ao igual a ela, "a necessidade de uma nova filosofia do desenvolvimento que ilumine a tira de decisões e as práticas de gestão. E cabe enfatizar o conceito "filosofia do desenvolvimento" (nem tanto ou não sozinha "economia") porque o que neste momento requer o planeta para fazer frente à questão ambiental é um novo esquema de pensamento integrado que tem que conceber-se em inter-relação com as chaves éticas, culturais e científicas, com chaves socio econômicas. Um modelo, enfim, que não pode vir só da racionalidade econômica" (Novo, 1996).

Parece evidente que a crise expõe a necessidade de revisar não só nossos patrões econômicos, mas também nossos enfoques éticos e científicos, que a sua vez influem em nossos modelos educativos e culturais, reprodutores de tais formas de pensamento. tratase, em definitiva, de passar dos velhos esquemas de domínio a um emergente paradigma ambiental no que nossos valores, visões científicas e modelos econômico-sociais se abram a novas formas de relação natureza - sociedade, que tenham possibilidades históricas no meio e comprido agrado para constituir-se em alternativas viáveis a atual situação.

A busca de um novo paradigma ambiental passa além por uma reflexão sobre a suposta "neutralidade científica" que alguns defendem e que a lamentável história de guerras e destruição ecológica do século XX se encarrega de questionar (NOVO, 2003). Coincidimos então que a dimensão científica de quem investiga não pode desligar-se de sua dimensão humana e social, de sua dimensão educativa. Uma tarefa verdadeiramente científica deve estar impregnada de valores, de modo que quem a realize se comprometa 
não só com o que faz mas também com os possíveis usos e consequências de seu trabalho. Daqui a importância que lhe concedemos à educação ambiental, não só dos educandos, mas também dos docentes. Através dos processos educativos é possível contribuir a deconstruções do velho imaginário de dominação que nos persegue, um mundo em contínuo crescimento e desigual partilha. A educação tem também a provocação e a possibilidade de potencializar os novos valores, de imaginar cenários alternativos. Educar ambientalmente é, assim, uma oportunidade para contribuir à emergência do novo paradigma. As novas formulações que neste sentido se foram alcançando são, por definição inacabadas, sujeitas a uma constante construção. Isso exige que nossa aproximação a esta tarefa se realize da abertura e a busca, sem cair em dogmas ou posições extremas e absolutas. Maria Novo assume que neste novo paradigma interpretativo da realidade, o trabalho científico se impregna de perguntas éticas que nos interpelam constantemente. Desde este enfoque, o problema ambiental é muito mais que uma questão de eficiência: é um problema de consciência. "Visto assim, - diz- o novo paradigma ambiental é uma ocasião para o abraço tanto tempo pendente entre o discurso científico, o mundo da ética, o contexto cultural, a arte, a história... Expõe a chegada do sujeito, carregado de valores e responsabilidades, mas também de sonhos, de sentimentos, que iluminam e matizam aquilo que lhe diz a razão, para dar conta da vida em toda sua complexidade: mente e corpo; razão e sentimento; ontem e hoje; ordem e desordem; eficiência e consciência"5. A visão que defendemos está também sujeita aos novos critérios sobre o problema da sustentabilidade. Uma visão que enfatiza na busca constante dos novos paradigmas ambientais. Consequentemente, o reconhecimento de que estamos nessa busca nos leva a não definir de uma maneira fechada e acabada os critérios de sustentabilidade, mas se a observá-los em estreita relação com o reconhecimento e o respeito da diversidade, reconhecimento que se concreta de diversas maneiras no uso dos recursos e supõe trajetórias culturais e sociais bem diferenciadas segundo cada comunidade. Assim mesmo, é preciso considerar que, embora a necessidade de alcançar um desenvolvimento sustentável é global (é o planeta inteiro o que precisa situar-se em condições de sostenibilidad), as propostas não devem alcançar somente à economia mundial, (ainda aceitando que algumas das respostas têm que ser necessariamente globais, como as que afetam à mudança climática), mas também, e muito fundamentalmente, às economias e as culturas regionais e locais, por isso se requerem

${ }^{5}$ NOVO, M. (2003). El desarrollo sostenible: sus implicaciones en los procesos de cambio. Polis Revista Latinoamericana. 5, 1-18. 
soluções contextualizadas e articuladas. A provocação de imaginar e pôr em prática um novo conceito e uma nova gestão do desenvolvimento, conduz-nos, imediatamente, à recuperação das grandes pergunta que se perderam na trajetória do economicismo, interrogantes que deveriam informar sem desculpas qualquer decisão econômica: são os "para que", os "como" e os "para quem" do desenvolvimento (Idem, p.14).

O facto de confundir crescimento económico com desenvolvimento desvirtuou o conceito de bem-estar. Precisamos transitar para estratégias de desenvolvimento que façam um uso menos intensivo dos recursos, porque o crescimento do produto global pode ser pobre quando provoca a destruição ou o dano dos recursos naturais. Este novo enfoque exige mudanças de rumo nos desejos e as preferências dos consumidores, nos orientando para atividades benignas com o meio ambiente, de uma vez que se reduzem os consumos produtivos por unidade de produto final.

Um verdadeiro desenvolvimento pode requerer crescimento econômico (especialmente nos países pobres), mas não sempre ou não como única medida. $\mathrm{O}$ desenvolvimento implica fundamentalmente uma ordenação (ou ré ordenação) dos valores e dos critérios que têm que reger o uso e dos recursos e o acesso aos mesmos em condições de eqüidade. É o que denominamos visão cultural do desenvolvimento, uma nova filosofia que aponta para a distinção do qualitativo, distinção afogada nos últimos tempos pelas práticas economicistas, com um modelo produtivo que tenta pôr preço a tudo o que existe.

Aproximar-se dessa problemática do âmbito educativo, tentando identificar suas causas e tratando de descobrir os modelos de utilização dos recursos que subjazem à crise, é a grande provocação que hoje tem o mundo exposto da educação, e no caso de Angola é uma provocação que não pode deixar de atender-se. A partir desta compreensão profunda, resulta possível abordar a tarefa educativa que temos diante como uma contribuição à mudança que o país propõe.

É este o enfoque que terá que lhe imprimir, nas condições atuais de Angola aos processos vinculados à educação ambiental, onde a sostenibilidad e a criação de uma mentalidade de produtores e não de consumidores seja de vital importância para um pais que, em vias de desenvolvimento, não escapa da tendência mundial da maioria dos países mais desenvolvidos: a busca do crescimento econômico ascendente como prioridade, em detrimento da qualidade ambiental. Solo superando esta limitação pode aspirar-se a que o nível de vida seja coerente com a qualidade de vida da população. 
A busca de alternativas para obter a educação ambiental começa a aparecer científica e pedagogicamente, e forma parte do cotidiano acionar escolar em cada país. No caso de Angola, a preocupação ambiental foi incluída no Programa de desenvolvimento Ambiental do Ministério de Urbanismo e ambiente do Governo de Angola, cujo relatorio do 2006 estabelece as bases para uma política ambiental dentro dos centros educacionais (MINAA, 2006) ${ }^{6}$.

É por esta razão que os educadores ambientais em Angola estão trabalhando com as comunidades rurais, as instituições ambientais, a juventude estudiantil e a comunicação social no desenvolvimento de capacidades e conhecimentos cidadãos para responder às mudanças ambientais e sociais, e desenvolver formas de vida mais sustentáveis.

A Educação Ambiental permaneceu desde seu surgimento, em estreita relação com a noção de meio ambiente e a forma em que este é percebido, não só em seus aspectos físico-naturais a não ser de uma perspectiva mais ampla, tendo em conta também seus aspectos econômicos e sócio-culturais. portanto, ao assumir a concepção sobre meio ambiente com um enfoque holístico e integrador, faz-se referência a um sistema complexo e dinâmico, de inter-relações ecológicas, socioeconômicas e culturais que evolui através do processo histórico da sociedade, abrange a natureza, a sociedade, e o patrimônio histórico-cultural criado pela humanidade em seu suceder.

É esta uma concepção mais integradora sobre Educação Ambiental, onde se trabalha como uma dimensão mais da educação integral do sujeito, passando de uma educação orientada à preservação da natureza, para outra mais próxima ao Desenvolvimento sustentável, que tem como objetivo principal restabelecer as condições de interação homem-homem e homem-natureza com um enfoque crítico e innovador (Silva, 2014) $)^{7}$

A partir destes presupostos, a Educação Ambiental deve ser abordada como uma dimensão que sustente todas as atividades, e considere os aspectos físicos, biológicos, sociais e culturais; um processo de reconhecimento de valores e classificação de

\footnotetext{
6 Programa de Desenvolvimento ambiental. Ministério de Urbanismo e ambiente. Governo de Angola. Relatorio do estado general do ambiente em Angola. MINAA 2006, Capítulo 2.

${ }^{7}$ Eciele Aparecida Da Silva, tese em opção ao título de Doutor em Ciências Pedagógicas. "Estratégia de formação contínua para a Educação Ambiental dos docentes do Ensino Básico nas escolas do município Ribeirão Cascalheira, Mato Grosso, Brasil”, Santa Clara, 2014.
} 
conceitos, analisando as atitudes do homem com relação ao médio para entender e apreciar as inter-relações entre os seres humanos, suas culturas e seus meios biofísicos. Nesse sentido, a Educação Ambiental se converte em uma condição absolutamente necessária para estabelecer processos de mudanças do comportamento de todos os membros da sociedade, sobre tudo no que se refere a sentimentos e valores orientados por compromissos com o meio mediante o qual se estabelecem as relações sociais e de todo tipo, contribuindo a uma identidade planetária vinculada aos valores de respeito e cuidado com o ambiente. A adopção de uma política ambiental mais eficiente, propiciarão alternativas viáveis para minimizar os danos ao meio ambiente, natural e social, mediante a adoção de leis mais rigorosas, com a colaboração de educadores mais comprometidos, através de um processo de formação contínua adequado, unido a uma política que priorize mais a investigação e o desenvolvimento de estratégias educativas coerentes e sistemáticas.

Em estudos angolanos se realça que a educação ambiental é um processo de ensino aprendizagem de transformação social onde os disímiles participantes são considerados o mesmo como educadores que como aprendizes. Isto significa que neste tipo de processo a educação ambiental inclui uma abordagem crítica, holístico e interdisciplinar sobre os vários problemas que afetam a nossa sociedade. Desta forma, tanto os educadores como os alunos têm a possibilidade de apoiar a construção de um mundo melhor que esteja direccionado pelo alcance de sociedades mais equilibradas e sustentáveis. Não só é importante contar com conhecimentos e atitudes, a não ser com o desenvolvimento de um espírito de responsabilidade e solidariedade.

Estas condições fazem possível que uma sociedade possa confrontar os problemas ambientais com êxito, e implica efetuar certas mudanças de comportamentos da sociedade de cara ao meio ambiente, e neste sentido o professor deve desempenhar um rol decisivo. Uma adequada formação científica dos professores, permitirá capacitar para o desenho, implementação e avaliação das tarefas de educação ambiental que os estudantes possam levasse efeito no processo docente educativo. A busca de uma resposta eficiente a este problema, é uma das questões de maior atualidade no mundo de hoje, e em Angola em particular, onde a preparação do docente através da formação contínua é uma necessidade vital para obter efetividade na educação. Entretanto, é necessário e urgente que se reflita sobre a qualidade da educação oferecida nas escolas, e voltar a revisar e analisar as atuais metodologias pedagógicas em consonância com os resultados obtidos desta prática. Há 
um consenso entre os educadores referidos a que a forma de ensino que vem sendo desenvolvida nas instituições não é adequada à logística ambiental. Entre os muitos desafios que Angola deverá enfrentar neste século, está a situação do sistema de ensino, em especial, no relacionado com a educação ambiental como um eixo transversal que articule todo o currículo escolar.

\section{CONSIDERAÇÕES FINAIS}

A partir das insuficiências identificadas nas reflexões anteriores, e a carência de uma pedagogia de transformação, coerente e eficaz, faz-se necessário estudar as práticas pedagógicas dos professores das escolas públicas locais de Angola e pensar em uma estratégia metodológica inovadora, que seja capaz de responder à alta demanda de profissionais em favor da vida, da justiça social, da solidariedade, e de um novo paradigma de ensino, em especial para as questões inerentes ao meio ambiente. Compreender as questões ambientais além de suas dimensões biológicas, químicas, físicas, e incluir as sócio-políticas e humanísticas, exige a formação de uma cultura ambiental; para isso se faz necessária a superação dos profissionais da educação para que possam dirigir o processo de ensino-aprendizagem, e inculcar modos de atuação e valores que coletem a um comportamento ambientalmente responsável em seus estudantes. Mas sempre esta compreensão passará pela proposta de uma visão cultural do desenvolvimento que observe a relação estreita entre educação ambiental e desenvolvimento sustentável. É assim como se pode formar um estilo e um sentido de vida afim com a conservação e cuidado do entorno, que rompa um tanto com as formas tradicionais a que nos acostumamos. 


\section{REFERÊNCIAS BIBLIOGRÁFICAS}

Aznar, P. (1998). La Educación Ambiental en la Sociedad Global. Valencia: Universidatat de València.

Aznar, P. (2003). Participación de las agencias educativas en el desarrollo sostenible a nivel local: hacia una Agenda 21 escolar. Rev. Española de Pedagogía, 225, 223-242.

Ayes, G. N. (2006). Desarrollo Sostenible. La Habana: Editorial Científico-Técnica.

Ballesteros, J., \& Pérez, A. J. (1997). Sociedad y medio ambiente. España: Editorial Trotta.

Novo, M. (1996). La educación Ambiental: bases éticas conceptuales y metodológicas. Editorial UNESCO/ Universitas. España.

Novo, M. (2003). El desarrollo sostenible: sus implicaciones en los procesos de cambio. Polis Revista Latinoamericana. 5, 1-18.

Roque, M. (1998). La Educación Ambiental en el Contexto Cubano. Conferencia Magistral. En Memorias del I Congreso de Educación Ambiental en el marco de la I Convención Internacional sobre Medio Ambiente y Desarrollo. UNESCO-CIGEA.

Perez, R. R. (2002). La educación ambiental. Un reto para el desarrollo sostenible. La Habana: Editorial Pueblo y Educación.

SOLÍS, E. T. (2002). La ética ambiental y la educación ambiental: dos construcciones convergentes. In E. Leff (Coord.), Etica y Educación Ambiental. México: Pensamiento Ambiental Latinoamericano.

Velázquez, C. G. F. (2000). La Educación Ambiental en el Siglo XXI. Ed. Grupo Editorial Universitario.

Viana, E. O. A. (2000). Metodologia de Trabalho Científico, Um enfoque Didáctico da Produção Científica. São Paulo: Ed. Pedagógica e Universitária Ltda. 


\section{Legislação Consultada}

UNESCO-PNUMA (1978). Declaración Final de la Conferencia Intergubernamental sobre Educación Ambiental. Paris.

UNESCO-PNUMA (1987). Estrategia Internacional sobre Educación y Formación Ambiental para los 90 .

ONU (1995). Fomento de la educación, la capacitación y la toma de conciencia.

ONU - Agenda 21 Programa de Acción de la Conferencia Mundial sobre Medio Ambiente y Desarrollo de Naciones Unidas.

Conferência das Nações Unidas sobre o Meio Humano, reunida em Estocolmo do 5 aos 16 de junho de 1972.

Declaração de Rio sobre o Meio Ambiente e o Desenvolvimento, Rio do Janeiro, junho de 1992.

Lei de Base do Sistema Educativo Angolano.

Lei Constitucional de Angola.

Programa de Desenvolvimento ambiental. Ministério de Urbanismo e ambiente. Governo de Angola. Relatorio do estado general do ambiente em Angola. MINAA 2006, Capítulo 2. 